\title{
A EDUCAÇÃO NO CONTEXTO DAS POLÍTICAS SOCIAIŚ ATUAIS: ENTRE A FOCALIZAÇÃO E A UNIVERSALIZAÇÃO
}

\author{
EDUCATION IN THE CONTEXT OF PRESENT SOCIAL POLICIES: \\ BETWEEN FOCALIZATION AND UNIVERSALIZATION \\ L'ÉDUCATION DANS LE CONTEXTE DES POLITIQUES SOCIALES \\ ACTUELLES : ENTRE LA FOCALISATION ET L'UNIVERSALISATION \\ LA EDUCACIÓN EN EL CONTEXTO DE LAS POLÍTICAS SOCIALES \\ ACTUALES: ENTRE LA FOCALIZACIÓN Y LA UNIVERSALIZACIÓN
}

Dalila Andrade Oliveira *

\section{RESUMO}

O presente artigo discute a educação como política social no contexto de reforma educacional em curso no Brasil desde a primeira metade da década de 1990. Parte da constatação de que $o$ País viveu um intenso processo de reformas educacionais, expresso em açóes e medidas que alteraram a configuração do sistema, bem como o objetivo das politicas. A partir de algumas referências teóricas que, fundamentadas em estudos e pesquisas empiricas, discutem os processos de reforma do Estado nos países da América Latina, identifica clara orientação de focalização da politica educacional no Brasil, obedecendo à mesma tendência evidenciada na condução das políticas sociais em geral. Observa que tal orientação se realiza no âmbito de reformas mais complexas que envolvem a administração pública, adotando modelos de desregulamentação e descentralização que permitem a focalização das políticas sociais nos mais pobres, em detrimento de politicas universais.

Palavras-chave: Politica educacional. Politica social. Reforma educacional. Educação. América Latina.

* Doutora em Educação pela Universidade de São Paulo (USP, 1999). Professora do Programa de PósGraduação em Educação da FAE/UFMG. Membro da coordenação da Rede Latino-americana de Estudos Sobre Trabalho Docente - Rede Estrado/Clacso. Pesquisadora do CNPq (dalila@fae.ufmg.br). 
O presidente Luiz Inácio Lula da Silva, na abertura da $4^{a}$ Reunião do Grupo de Alto Nível de Educação para Todos, disse que o Brasil "está comprometido de corpo e alma" com as metas do milênio definidas pela ONU, dentre as quais se destacam o combate à pobreza e o acesso de todos à educação. Essa reunião, realizada em 8 de novembro de 2004, teve o objetivo de avaliar o andamento das metas definidas pelo Fórum Mundial da Educação, em Dacar, no Senegal, em 2000, para serem atingidas até 2015. Tais compromissos têm sua origem na Conferência Mundial sobre Educação para Todos, realizada em Jomtien, em março de 1990, sob os auspícios da ONU. O esforço concentrado em torno das reformas educacionais, que passariam a ser implementadas nos países mais pobres e populosos do mundo, a partir daí, só se justifica ante o processo de reestruturação capitalista, fundado na transnacionalização do capital e vulgarmente conhecido por globalização.

Os vínculos entre educação e desenvolvimento econômico, que durante o processo de industrialização por que passaram os países desenvolvidos nas primeiras décadas do século XX e a partir dos anos 1930 os países latino-americanos, começaram a ser questionados no início da década de 1980. Tal questionamento é resultado da evidência do crescente aumento da riqueza das nações e empobrecimento das populações. Esse movimento contraditório demonstra que as políticas redistributivas são essenciais ao desenvolvimento social. Verificou-se que não basta desenvolver economicamente uma nação se não são constituídos instrumentos para que sua população também atinja melhores patamares de vida. Porém, tal constatação não foi suficiente para negar a relação entre educação e economia.

Mas, se o aumento estrondoso da riqueza no mundo nos anos 1980 e 1990, acompanhado paradoxalmente pelo crescimento da pobreza, verificado nos relatórios mundiais do Programa das Nações Unidas para o Desenvolvimento Humano - PNUD, não foram suficientes para convencer os governos a redirecionarem suas políticas distributivas, com certeza influenciaram as orientaçôes que os organismos internacionais ligados à ONU passaram a adotar para os países pobres e populosos.

O contexto de globalização, caracterizado pelo desenvolvimento das forças produtivas e da incorporação de novas tecnologias aos processos de trabalho, teve como conseqüência o crescente desemprego e a chamada "flexibilização nas relações de trabalho". A globalização trouxe um novo cenário, que, a despeito do fetiche com que é apresentado, sobretudo no final do segundo milênio - como a nova era, a era da automação, da robótica, da informatização e das mudanças nos padrões de vida de todos os cidadãos, prometendo integrá-los em uma "aldeia global" -, resultará em uma crise social que condena a maioria da população mundial a condiçôes indignas de vida. ${ }^{1}$

Robert Castel (1997), discutindo as transformações sociais advindas do processo acima mencionado, caracteriza-as como um questionamento da função integradora do trabalho hoje na sociedade. Em um estudo histórico de grande densidade, o autor vai demonstrando como o sistema de proteçōes e garantias sociais vinculado ao trabalho vai sendo desmontado para chegar-se ao que caracteriza como "um processo de precarização que atinge as situações do trabalho, no sentido da sua re-mercantilização e de soluções na ordem do mercado, como efeito particular da globalização" (p.166-167). 
A partir de uma retomada histórica, o autor situa no final do século XIX o processo de transformação do trabalho em emprego. Para ele, é com o avanço do capitalismo, que traz o desenvolvimento da industrialização e da urbanização, que ocorre uma maior regulamentação da vida social, produto da normatização das relações de trabalho. $\mathrm{O}$ trabalho passará, assim, nos dizeres do autor, da "condição íntima e miserável" à de veículo para uma condição de vida digna aos que não têm propriedade. A regulamentação do trabalho, um processo que se dá por meio de lutas intermináveis, em que os sindicatos aparecem como importantes protagonistas, vai caracterizar a sociedade do salariado. Na realidade, a passagem do trabalho ao emprego é marcante na estrutura dessa sociedade, que Castel denomina salariado. $\mathrm{O}$ desenvolvimento industrial e urbano foi resultando em novas formas de vida e no acúmulo de conquistas trabalhistas, traduzidas em direitos legais, formando a base de uma nova regulação social, em que sindicatos, Estado e empresários são interlocutores.

A regulamentação do trabalho, os direitos trabalhistas e previdenciários, o futuro garantido mediante a aposentadoria, trouxeram finalmente para os trabalhadores a possibilidade de viverem da venda de sua força de trabalho. Para muitos, o objetivo na vida passou a ser a obtenção de um emprego formal e regulamentado, e de preferência estável. Nas palavras de Castel (1997, p. 170):

Pode-se dizer, efetivamente, que esse tipo de proteção, de regulação, ou seja, direito do trabalho, seguridade social, foi, inicialmente, ligada ao salariado, e, mesmo, ao pequeno salariado, e que se difundiu no conjunto da estrutura social. $\mathrm{O}$ salariado se consolidou e se dignificou, se ouso dizer, e passou mesmo a ter um papel de atração, em torno do qual o conjunto da sociedade moderna se organizou.

Não se trata de afirmar que a classe operária teria chegado ao paraíso; não, essa sociedade se desenvolve de forma rigidamente hierárquica, fundada na exploração, permanecendo, portanto, as injustiças sociais. Mas é, inegavelmente, uma sociedade em que cada indivíduo tem a possibilidade de desfrutar de um mínimo de estabilidade e segurança. Esse modelo de regulação social, denominado por alguns de sociedade do pleno emprego, ou anos dourados do capitalismo, ${ }^{2}$ será responsável pela sedimentação dos vínculos entre educação e desenvolvimento econômico. Tal modelo de regulação social, ${ }^{3}$ levado a termo nos países centrais, possibilitará o desenvolvimento dos sistemas escolares, a partir de um novo modelo de êxito, em que a mobilidade social se realiza não mais pela livre iniciativa, mas pela obtenção de um bom emprego numa grande corporação. A educação passou, então, a ser um requisito indispensável ao sucesso profissional e pessoal. ${ }^{4}$

Se os sistemas escolares no seu nascedouro tiveram estreita relação com o surgimento dos Estados nacionais, pela importância atribuída à língua e outros fatores de integração nacional, dos quais a escola é difusora, ${ }^{5}$ fortaleceram-se muito mais com o desenvolvimento do capitalismo monopolista, da grande corporação, em que a educação passa a ser importante meio de seleção e inserção no mercado de trabalho.

Segundo Carnoy (1993), os primeiros movimentos de reforma educacional são orientados para o local de trabalho e, só posteriormente, é que estes passam a ser dirigidos a 
atender os anseios de cidadania. Embora a referência desse autor seja a sociedade norteamericana, observa-se essa tendência em vários países, ou seja, nota-se que os processos de reforma educacional em diferentes realidades nacionais acompanham, mais ou menos, o movimento por ele descrito. O que o autor chama a atenção e, para nós, é motivo de discussão, é o fato de que as reformas educacionais que objetivaram a universalização do ensino - resultantes justamente do crescimento de forças sociais que se contrapōem à acumulação de capital - custaram caro ao poder público. $\mathrm{O}$ acesso universal à educação e, conseqüentemente, às demais políticas sociais, será resultado do processo de regulamentação do trabalho e de novas formas de regulação social, que surgem com o desenvolvimento do capitalismo. Entretanto, as políticas sociais de cunho universal, características do Estado de bem-estar social, financiadas pelo poder público, serão fortemente questionadas com o desmonte do referido modelo de regulação, que começa a ocorrer já no final dos anos 1970.

Durante esse período relativamente estável de regulação social, calcada na regulamentação do trabalho e no acesso às políticas sociais universais, observa-se na sociedade o crescimento da noção de direitos sociais e de Estado de Direito. Entendendo o direito como a regulamentação das relaçôes fundamentais para a convivência e sobrevivência do grupo social, e sendo ele, ao mesmo tempo, o principal instrumento através do qual as forças políticas, que têm nas mãos o poder dominante em uma determinada sociedade, exercem o próprio domínio, ${ }^{6}$ há que se considerar que as noçōes de direito e de Estado podem assumir diferentes configurações, dependendo do período e contexto histórico em que se constituem. Sendo assim, pode-se considerar que a via jurídica tem se convertido em importante espaço de disputa, com o crescimento e fortalecimento das instituições sociais que representam os interesses dos trabalhadores em seus diferentes modos de atuação. Essa talvez seja a mais relevante característica da política que marca o período aqui rapidamente esboçado. A organização sindical, partidária e outras instituições no âmbito da sociedade civil passam a exercer preponderante papel na definição das políticas sociais nos países em que o Estado de bem estar social encontrou sua forma plena.

\section{AS POLÍTICAS SOCIAIS NO BRASIL: A REGULAMENTAÇÃO DAS RELAÇÕES DE TRABALHO}

Tomando o significado de política como derivado do adjetivo originado de polis, que significa tudo que se refere à cidade e, conseqüentemente, ao que é urbano, civil e público, Bobbio (1992) irá afirmar que na época moderna tal termo se expandiu, passando a ser comumente utilizado para indicar a atividade, ou conjunto de atividades que, de alguma maneira, tem como referência a polis, o Estado. Assim, o conceito de política entendida como forma de atividade ou de práxis humana, está estreitamente ligado ao poder, sendo que o poder pode ser definido como a relação de domínio do homem sobre o meio ou sobre outros homens. Bobbio (1992) observa, porém, que o poder político pertence à categoria do poder do homem sobre outro homem e não à do poder do homem sobre a natureza. Lembra ainda, o autor, que há várias formas de poder do homem sobre o homem e que o poder político é apenas uma delas. Ressalta 
também que, embora a possibilidade de recorrer à força seja o elemento que distingue o poder político das outras formas de poder, isso não significa que ele se resolva no uso da força. Tal uso é uma condição necessária, mas não suficiente, para a existência do poder político. Sobre os fins da política, o autor ainda adverte que:

a única coisa que se pode dizer é que, se o poder político, justamente em virtude do monopólio da força, constitui o poder supremo num determinado grupo social, os fins que se pretende alcançar pela ação dos políticos são aqueles que, em cada situação, são considerados prioritários para o grupo (ou a classe nele dominante) (BOBBIO, 1992, p. 957).

Sendo assim, o fim da política estaria relacionado aos interesses de uma determinada organização, social que se rege pelo uso exclusivo do poder coativo. Tal observação, é indispensável para a compreensão do contexto em que emanam as políticas sociais. $\mathrm{O}$ processo de formulação, implantação, avaliação e controle das políticas públicas que visam ao atendimento de demandas sociais específicas relaciona-se com as escolhas que em determinadas conjunturas os governos fazem. A definição dos objetivos das políticas de cunho social, o seu caráter e extensão, estão vinculados a projetos e concepções de governo e de organização social. Nesse sentido, Abranches (1998, p. 10) observa que:

se a política fosse apenas contrato, a política social seria cláusula inarredável do capítulo das obrigaçôes coletivas, a cargo do Estado. Política, porém, é conflito. Oposição e contradição de interesses. Conflito negociado, regulado por instituiçôes políticas de natureza vária, condicionado por mediações que tornam possível reduzir os antagonismos e projetá-los em um movimento positivo. Política é, também, poder, transformando-se, freqüentemente, em um jogo desequilibrado, que exponencia os meios dos mais poderosos e reduz as chances dos mais fracos. Quem detém instrumentos eficazes de pressão tem maior probabilidade de obter mais da ação do Estado do que aqueles dependentes dessa própria ação para conseguir o mínimo indispensável à sua sobrevivência.

A política social reflete, assim, a direção política das relações econômicas. A política social intervém no hiato derivado dos desequilíbrios na distribuição em favor da acumulação e em detrimento da satisfação de necessidades sociais básicas, assim como na promoção da igualdade. A ação social do Estado pode dizer respeito tanto à promoção da justiça social quanto ao combate da miséria, mas, segundo Abranches (1998), tratamse de objetivos distintos. Sendo assim, a ação governamental reflete escolhas em um quadro de conflito, não havendo, portanto, governos imparciais, visto que as escolhas sempre envolverão julgamento de valor, ainda que estejam ancoradas em avaliações técnicas.

Se, como afirma Abranches (1998, p. 14), "a política social praticada na maioria dos países industrializados, e naqueles que chegaram a conquista do Estado de bem estar, teve por objetivo compensar o mal-estar, os custos sociais, os efeitos perversos derivados de ações indispensáveis à acumulação, de outras políticas governamentais e do próprio progresso, que, ao induzir mudanças, pode colocar certos grupos em situação de dependência”, em países como o Brasil a situação foi outra. 
As políticas sociais no Brasil foram desenvolvidas em um contexto de muita contradição, marcado pela desigualdade no acesso e na extensão. Tais políticas, em especial aquelas de cobertura ampla, universal, tiveram um desenvolvimento tardio, se comparado ao da maioria dos países de mesmo porte econômico. O processo de industrialização que ocorreu no Brasil, com maior veemência a partir dos anos 1930, resultou em uma gama de políticas regulamentadoras restritas a setores da classe trabalhadora urbana e industrial. Por mais de três décadas os trabalhadores rurais brasileiros não puderam gozar das mesmas prerrogativas e direitos conferidos aos trabalhadores urbanos. A Consolidação das Leis do Trabalho - CLT, de 1943, o mais importante instrumento de regulamentação das relações de trabalho no Brasil, garantiu no plano individual, para os trabalhadores, direitos tais como carteira de trabalho, direito a férias, a horas-extras; no plano coletivo, possibilitou o agigantamento da organização sindical. A estrutura sindical que se consolida nas décadas seguintes à CLT, no Brasil, é caracterizada pelo corporativismo, e suas ações pelo legalismo. Somaram-se a essas políticas, no mesmo sentido da expansão de políticas sociais dirigidas aos trabalhadores urbanos, a previdência social, por meio dos institutos de pensão, até a criação do Instituto Nacional de Previdência Social - INPS e a criação, posteriormente, do Fundo de Garantia por Tempo de Serviço - FGTS, que trouxe consigo a política de habitação, através da criação do Banco Nacional de Habitação - BNH. Somam-se ao acesso a essas políticas dirigidas aos trabalhadores urbanos os serviços oferecidos pelas agências do Sistema S (Sesi, Senai, Sesc, Senac, entre outras), da mesma forma com acesso restrito.

Observa-se, assim, nesse período, uma forte regulamentação de políticas voltadas ao atendimento dos trabalhadores urbanos e, principalmente, da indústria, constituindo-se uma sociedade em que ser detentor de um trabalho formal e regulamentado permite uma vida com maior acesso aos bens públicos. Porém, se há essa ampliação dos direitos sociais vinculados ao trabalho observada nesse momento, o mesmo não se pode afirmar com relação aos direitos civis e políticos (DUARTE, 2002, CARVALHO, 1995).

As décadas de 1960 e 1970 foram marcadas pelo autoritarismo, imposto por mais de 20 anos de regime militar, instalado por meio de um golpe de Estado, mas também expressaram alguns ensaios de ampliação de políticas sociais de cobertura ampla e extensão universal. No plano educacional, a ampliação do direito à educação de quatro para oito anos constitui-se em importante medida de expansão da escolaridade dos brasileiros. O final dos anos 1970 e início dos 1980 foram marcados pela luta em favor da democratização da educação, da ampla defesa do direito à escolarização para todos, da universalização do ensino e da reivindicação por maior participação da comunidade na gestão da escola. A Constituição Federal de 1988, em que pese suas contradições, consolidou em seu texto muitas das bandeiras que os movimentos sociais empunharam nas décadas antecedentes, não só no que se refere ao maior acesso à educação, mas aos direitos sociais em geral. 


\section{A REFORMA EDUCACIONAL NO ÂMBITO DA REFORMA DO ESTADO BRASILEIRO: DESREGULAMENTAÇÃO E DESPROTEÇÃO}

As políticas sociais na realidade brasileira atual visam, prioritariamente, ao alívio à pobreza. Retirar da condição de miséria aqueles que sequer conseguiram alcançar as condições mínimas de sobrevivência. A orientação percebida nas ações do governo Fernando Henrique Cardoso e que, em certa medida, tem sido levada a termo no atual governo de Luiz Inácio Lula da Silva, no que se refere à condução das políticas sociais em geral, revela clara escolha. Depois de duas décadas de intensas manifestações, que expressaram fortes pressões populares pela ampliação dos direitos sociais, da cobertura universal de políticas de maior acesso à saúde, educação, habitação e previdência, entre outros, os anos 1990 foram marcados por reformas no âmbito do Estado que priorizaram o corte no gasto social. As importantes conquistas consagradas na Constituição Federal de 1988 foram paulatinamente sendo retiradas do plano das leis, por meio de instrumentos jurídicos que exigiram em alguns casos até mesmo reforma constitucional, sendo que em muitas matérias a norma sequer chegou a tornar-se fato. No quadro de reformas que o Estado brasileiro viveu na década passada, assistiu-se a uma opção clara por modelos de políticas sociais de cunho compensatório e focalizadas nas populações mais vulneráveis.

Salama e Valier (1997), discutindo a recente evolução dos sistemas de proteção social nos países latino-americanos, chamam a atenção para o fato de que se nota uma grande defasagem entre direito e realidade. Observam que, na realidade desses países, universalização e homegeneização parecem bem distantes. Os direitos sociais reconhecidos em muitos desses países foram apenas formais, dada a magnitude do setor informal, que exclui dos sistemas de proteção um grande número de pessoas e estabelece discriminações entre os beneficiados, em proveito dos mais ricos (uma distribuição diferenciada dos benefícios em termos de favores e privilégios, resultantes do clientelismo).

$\mathrm{Na}$ análise das políticas sociais liberais implantadas nos países latino-americanos, os referidos autores destacam três características centrais, que são apresentadas abaixo de maneira resumida:

1a) Políticas sociais orientadas para os muito pobres - por serem incapazes de suportar os custos das reformas e de se protegerem, os mais pobres serão o alvo das ações sociais governamentais. São políticas destinadas a garantir às populações mais vulneráveis um mínimo de serviços de primeira necessidade e de infra-estrutura social. O caráter focalizado que apresentam nos muito pobres é justificado pela necessidade de combate à extrema pobreza. Observam, assim, que face a essa focalização, a política social tende a perder seu caráter universal e a se tornar um mero paliativo.

2a) Políticas sociais de assistência-benfeitoria e de privatização - têm por objetivo ajustar a relação entre seguro e assistência. Observam os autores que: "Na implantação desta política, o Banco Mundial e alguns governos de países subdesenvolvidos recorreram com freqüência às Organizações Não Governamentais - ONGs, como instâncias intermediárias, fundamentais tanto para identificar os grupos mais desfavorecidos, quanto para distribuir as ajudas." (SALAMA; VALIER, 1997, p. 119). Paralelamente, as 
camadas médias vão abandonando cada vez mais o setor público, face a sua deterioração, e voltando-se para o setor privado. A privatização é, como afirmam os autores, a outra face da política social focalizada nos extremamente pobres.

3a) Politicas sociais descentralizadas e recorrendo a uma participação popular - o recurso à descentralização das políticas sociais justificado na busca de "maior eficiência e racionalização dos gastos, bem como a interação mais fácil entre os recursos governamentais e não governamentais para financiar as ações sociais" (SALAMA; VALIER, 1997, p. 120). O apelo à caridade, ao apoio comunitário, passam a ser condições vitais para a realização dessas políticas. Em geral, as ações descentralizadas se realizam, nesse modelo, por meio de contratos entre o governo central e governos subnacionais, como no caso brasileiro as chamadas parcerias entre União, Estados e Municípios, bem como outras instituiçôes da sociedade civil e ONGs.

De acordo com Abrúcio (1999), o estabelecimento de relações contratuais por parte do Estado baseia-se em três pressupostos: o primeiro é de que, numa situação de falta de recursos, a melhor forma de aumentar a qualidade é introduzir relaçôes contratuais de competição e de controle; o segundo, quase como conseqüência do primeiro, é de que a forma contratual evita a situação de monopólio; e, finalmente, o terceiro, refere-se à maior possibilidade que os consumidores (supostamente) têm de controlar e avaliar o andamento dos serviços públicos, a partir de um marco contratual.

Necessário ressaltar que a política social, como obrigação permanente do Estado, é aquela voltada para propiciar à população necessitada um patamar mínimo de bem-estar. Já as políticas sociais orientadas ao combate à pobreza têm por objetivo eliminar a destituição, num espaço de tempo definido, incorporando os despossuídos aos circuitos regulares da vida social e compensando as principais carências que põem em risco a sobrevivência e a sanidade das pessoas (ABRANCHES, 1998). Por isso, elas são específicas, temporárias e combinam ações sociais compensatórias com aspectos das políticas sociais permanentes, em que o Estado tem estratégias próprias de intervenção. Ao contrário das políticas sociais permanentes, que deveriam ter como meta a universalização, as políticas compensatórias, de eliminação da pobreza, são absolutamente seletivas.

Salama e Valier (1997) afirmam que as políticas sociais liberais são o aspecto mais novo das políticas que, ligadas ao processo de reestruturação das funções do Estado, sobre as bases do liberalismo econômico, foram propostas pelos organismos internacionais e implementadas em alguns países subdesenvolvidos, a partir do final dos anos 1980, incluindo os países da América Latina. Essas políticas aparecem, sobretudo, como resultantes de uma crítica ao Estado de bem-estar social.

A partir de alguns casos nacionais estudados, os autores acima referidos observam que as reformas de Estado, ocorridas durante os anos 1990 nos países latino-americanos, trouxeram uma orientação mais ou menos convergente com o modelo britânico de reforma estatal, implantado no período Tatcheriano. Em tais reformas, observa-se a firme orientação de redução dos gastos públicos destinados à proteção social, principalmente dos pobres, e a priorização da assistência social aos mais pobres, em geral com fundos públicos criados para esse fim, com existência provisória (DRAIBE, 1998, DINIZ, 1998, SALAMA; VALIER, 1997, ABRUCIO, 1999). O Estado passa a se relacionar com os cidadãos dividindoos em dois grupos: os contribuintes/consumidores e os destituídos/assistidos. 
No caso da educação, a descentralização passa então a nortear as reformas propostas para a organização e administração dos sistemas de ensino, seguindo as orientações gerais no quadro de reformas do Estado. Ressalta-se, nesse contexto, o relativo recuo que o Estado nacional vem apresentando, tanto na sua participação direta no setor produtivo, quanto em outras esferas de seu domínio, provocando mudanças nas formas de financiamento das políticas sociais, que passam, via de regra, pelo recurso à iniciativa privada, seguindo a tendência observada por Salama e Valier (1997) em outros países latinoamericanos. Assim, observa-se que, na tentativa de equacionar as exigências populares de maior acesso aos serviços públicos e a necessidade de responder por maior eficiência nos já ofertados, o governo brasileiro tem conduzido mudanças nos aspectos gerenciais das políticas públicas, orientadas por critérios de racionalidade administrativa, fundados na economia privada. Contudo, tais políticas têm focalizado o atendimento aos muito pobres (SALAMA; VALIER, 1997), às populações vulneráveis, sob a justificativa de que os recursos disponíveis não são suficientes para atender a todos em igual proporção.

Segundo Draibe (1998), a partir de uma análise comparativa da tendência de reformas de políticas e programas sociais na América Latina, considerando a experiência de sete países, o receituário predominantemente proposto para as mudanças na área social apoia-se em três grupos de justificativas: os episódios de ajustamentos fiscais da primeira metade dos anos 1980, que exigiam do gasto social maior eficiência e principalmente uma forte adequação aos objetivos macroeconômicos; a reorientação do gasto social, para atender ao previsível empobrecimento da população, resultante dos impactos do ajustamento recessivo sobre emprego, renda e redução dos serviços sociais, levando à focalização do gasto, à opção por fundos sociais de emergência e por programas compensatórios dirigidos exclusivamente aos grupos pobres e vulneráveis; e, por fim, o gasto social teria de priorizar ações básicas de saúde, nutrição e, principalmente, programas de caráter produtivo, como investimento em "capital humano".

As políticas educacionais contemporâneas no Brasil espelham exatamente a tendência apontada por Draibe (1998), sendo que o Fundef e o Programa Nacional do Bolsa-Escola e, mais recentemente, o Programa Bolsa-Família, parecem constituir os melhores exemplos. Observa-se, assim, que o papel atribuído às políticas sociais nos contextos nacionais latino-americanos tem sido de atenuar ou cobrir o hiato existente entre a estrutura econômica e a população destituída das suas condições materiais básicas, indispensáveis a uma vida minimamente digna. Uma política para os que não conseguem ser cidadãos de fato.

\section{A POLIITICA EDUCACIONAL COMO POLÍTICA SOCIAL: APONTAMENTOS FINAIS}

A educação, como uma das mais relevantes manifestações de políticas sociais, assume nesse contexto de reforma a que se assiste nos países latino-americanos um caráter dual e contraditório. Ao mesmo tempo em que se afirma como uma política social de caráter universal - a ampliação da escolaridade e o crescimento do contingente de alunos atendidos nos sistemas e redes públicas, na maior parte dos países deste sub-continente, é um indicador desta tendência -, tem sido orientada também pela lógica da focalização. 
Esta segunda orientação tem conduzido a política educacional a se concentrar em medidas que asseguram o acesso e a permanência de grupos mais vulneráveis socialmente na escola. Como exemplo, as cotas para negros nas universidades públicas e os programas de distribuição de renda mínima, como o Bolsa-Escola.

Assim, observa-se que a política educacional no Brasil, atualmente, tem dado maior visibilidade a programas de inserção focalizada e dedicado menor atenção às questôes da universalização. Isto vem ocorrendo graças ao modelo de reforma educacional em curso desde o início dos anos 1990, conforme já comentado. A tentativa por parte do Estado de capitanear o processo de mudanças na educação, que ocorre a partir da primeira metade da década de 1990, foi buscada no discurso da técnica e da agilidade administrativa. Os conceitos de produtividade, eficácia, excelência e eficiência serão importados das teorias administrativas para as teorias pedagógicas, ao mesmo tempo em que a escola passa a ter maior importância como unidade administrativa. Porém, essa não é uma tendência observada só nas políticas educacionais; ao contrário, passa a ser uma orientação dominante na administração pública brasileira.

O texto da Emenda Constitucional n. 19, de 1998, reflete com muita clareza a lógica racional impressa na reforma do Estado, iniciada no governo Fernando Henrique Cardoso e continuada no governo Lula. A possibilidade de criação das Organizações Sociais e dos Contratos de Gestão, firmada em lei, tem influenciado uma outra concepção de público, bastante presente no debate atual sobre a reforma universitária. O Prouni, um programa de política compensatória, claramente focalizado nos mais pobres - estudantes que não conseguiram ingresso nas mais conceituadas instituições universitárias do País -, vem legitimar e naturalizar uma noção de serviço, que se contrapõe à de direito. Perde importância a concepção de instituição escolar pública; a referência ao serviço, como produto que se tem acesso, passa a ser mais importante, naturalizando-se, assim, uma noção de atendimento, em que o financiamento é público, mas a oferta pode se dar no âmbito do setor privado.

A luta pela democratização do acesso à educação, entendida como um direito público, subjetivo, a que todos os cidadãos têm garantia, portanto de cobertura ampla e caráter universal, passa a ser reduzida a uma política de assistência social. Isto ocorre por meios vários, incluindo desde políticas de financiamento, de caráter mais permanente, a incentivos e premiação esporádicas.

$\mathrm{Na}$ realidade, as reformas educacionais implementadas nesse contexto exprimem, assim, a racionalidade presente na reforma do Estado brasileiro, cuja maior expressão é a reforma administrativa. Como já comentado, a suposta crise do modelo de administração pública vigente por décadas no País fez emergir outras formas de organização do serviço público, cujo eixo se assentou na flexibilidade administrativa. A administração pública passou a contar com modelos descentralizados de gestão das políticas sociais. Trata-se de um processo que pressupõe a focalização das políticas públicas nas populações muito vulneráveis, a partir da definição de um padrão mínimo de atendimento (custo mínimo aluno-ano, do Fundo de Desenvolvimento e Manutenção do Ensino Fundamental e Valorização do Magistério - Fundef é o melhor exemplo); a descentralização do atendimento do nível central para o local; a desregulamentação, para permitir maior flexibilidade orçamentária e administrativa, sobretudo para recorrer a fontes alternativas de custeio. 
Desta forma, a reforma da educação básica, realizada no Brasil a partir do início dos anos 1990, que teve como principal objetivo a expansão da escolaridade, focalizou o ensino fundamental, por meio de políticas de planejamento e financiamento, tais como o Fundef, criado pela Lei 9.424/96 e o Plano Nacional de Educação - PNE, transformado em Lei, sob o n. 10.172, de janeiro de 2001, que atribuem prioridade aos indivíduos entre sete e 14 anos. O ensino fundamental, durante os oito anos de governo Fernando Henrique Cardoso, foi a única etapa da educação básica que contou com financiamento seguro. Além dos recursos anuais do referido fundo, contou ainda com verbas do salárioeducação e outras formas especiais de financiamento, como o PDDE - Programa Dinheiro Direto na Escola, o Fundescola e outros programas inseridos no âmbito do Fundo Nacional de Desenvolvimento da Educação - FNDE.

Os procedimentos legais adotados no curso das referidas reformas tiveram como orientação a descentralização de ações administrativas e a repartição de recursos públicos destinados ao financiamento da educação em âmbito federal, estadual e municipal, estabelecendo, por meio do Fundef, um custo mínimo aluno-ano. Tal política resultou em um forte estímulo à municipalização, já que o atendimento ao ensino fundamental passou a ser prioridade dos municípios, além de consistir em uma possibilidade de recebimento de mais recursos, especialmente para as cidades mais carentes. Tais procedimentos só foram possíveis depois de mudanças significativas na legislação educacional atual, que passou a se caracterizar pelo seu aspecto desregulamentado, permitindo maior flexibilidade para que as unidades escolares buscassem formas de complementação orçamentária ao custo mínimo aluno-ano, junto à comunidade local, envolvendo parcerias com empresas e outras agências.

A descentralização, como orientação para o planejamento, embora não se configurasse como novidade, pois já estava prevista na reforma do Estado da década de 60, no Decreto n. 200, de 1967, assumiu novo caráter nas reformas dos anos 1990. Ela passa a contemplar os processos de flexibilização e desregulamentação da gestão pública, com a justificativa de busca de melhoria no atendimento ao cidadão/contribuinte, reduzindo as mediações existentes entre o Estado e o cidadão. Contudo, será por meio da tentativa de municipalização, defendida como a possibilidade de permitir às populaçóes maior controle sobre a gestão das políticas públicas, pela proximidade física com os meios de decisão e gestão, que o Estado buscará descentralizar a gestão e a implementação de políticas sociais. Deve-se considerar que tal política no Brasil envolve muitos riscos, especialmente se se considerar a diversidade dos municípios brasileiros: dos 5.506 municípios brasileiros, cerca de $75 \%$ têm menos de 20 mil habitantes e, destes, mais de um terço tem menos de 5 mil habitantes. Trata-se de uma realidade em que a maioria dos municípios apresenta reduzida capacidade de gestão administrativa.

A partir da Constituição Federal de 1988, a compreensão de Estado como poder público, envolvendo as três instâncias administrativas: União, Estados e Municípios, por meio do pacto federativo, interfere na gestão das políticas sociais. Contudo essa tem sido uma política conflituosa, em que diferentes articulaçôes institucionais têm se desenvolvido. Aos municípios cabe, em geral, as etapas mais básicas ou imediatas do atendimento. Cooperação recíproca, diferentes competências, regime colaborativo, provocaram um movimento ambivalente: ao mesmo tempo em que permitiram maior autonomia aos 
municípios e maior possibilidade de controle popular, têm servido também a novas estratégias e rearranjos de financiamento de políticas públicas e sociais que desresponsabilizam o poder central e sobrecarregam a comunidade. A municipalização, porém, é apenas uma das estratégias de descentralização da administração pública, pois outros instrumentos descentralizadores de planejamento e gestão das políticas sociais, que envolvem a relação com outras organizações da sociedade civil, sindicatos, associações e ONGs, também estão presentes nesse modelo.

$\mathrm{O}$ regime de colaboração entre as diferentes esferas administrativas passa a ser indispensável para a constituição, de fato, de um sistema de administração pública que focaliza $o$ atendimento nos mais necessitados, funcionando de maneira integrada e articulada, considerando-se as dimensões geográficas deste imenso país.

Contudo, a descentralização da educação, nas suas vertentes administrativas, financeiras e pedagógicas, ocorrerá não só como uma transferência de responsabilidade dos órgãos centrais para os locais, da União para os Estados e destes para os Municípios, como implicará também um movimento de repasse direto de certas obrigaçōes de órgãos do sistema para a escola. Assim a democratização da educação será compreendida pelo Estado como uma necessidade de procurar imprimir maior racionalidade a sua gestão.

O modelo de reforma de Estado e reforma educacional, aqui rapidamente abordado, tem ensejado a municipalização de algumas políticas sociais, sob o argumento da democratização do acesso, assim como tem promovido a focalização de políticas dirigidas aos grupos mais necessitados. Contudo, essas estratégias ignoram o fato de que as políticas sociais mínimas, as garantias básicas de uma vida digna em sociedade, sequer chegaram a ser generalizadas na maioria dos países latino-americanos, dentre os quais o Brasil é um destacado exemplo. A transferência das responsabilidades do poder central para o local, do Estado para a sociedade, do governo para o não-governo, sobretudo no que se refere à implementação e execução das políticas, tem colocado em risco importantes valores de integração nacional, bem como a preservação da história e do patrimônio público construído por muitas gerações.

\section{Notas}

1. Acerca das mudanças no padrão de vida dos indivíduos, ver: Bauman (2004) e Giddens (1991).

2. Cf:: Hobsbawm (1998).

3. Adoto aqui a noção de regulação social desenvolvida pela EFR, ver: Aglieta (1979).

4. Cf.: Mills (1987).

5. Ver: Popkewitz (1997).

6. Cf.: Bobbio (1992, p. 349). 


\section{Referências}

ABRANCHES, Sérgio Henrique Hudson de. Política social e combate à pobreza: a teoria da prática. In: .; SANTOS, Wanderley Guliherme dos; COIMBRA, Marcos (Orgs.). Política social e combate à pobreza. 4. ed. Rio de Janeiro: Zahar, 1998.

ABRUCIO, Fernando Luiz. Os avanços e os dilemas do modelo pós-burocrático: a reforma da administração pública à luz da experiência internacional. In: BRESSER-PEREIRA, Luís Carlos; SPINK, Peter (Orgs.). Reforma do Estado e administração pública gerencial. 3. ed. Rio de Janeiro: Fundação Getúlio Vargas, 1999. p. 173-199.

AGLIETTA, Michel. Regulación y crisis del capitalismo. Mexico: Siglo Veintiuno, 1979.

BAUMAN, Zygmunt. Amor líquido: sobre a fragilidade dos laços humanos. Rio de Janeiro: Zahar, 2004.

BOBBIO, Norberto et al. Dicionário de política. 4. ed. Brasília: Edunb, 1992.

BRASIL. Constituição da República Federativa do Brasil. 18. ed. São Paulo: Saraiva, 1998.

BRESSER-PEREIRA, Luís Carlos. Da administração pública burocrática à gerencial. In: .; SPINK, Peter (Orgs.). Reforma do Estado e administração pública gerencial. 3. ed. Rio de Janeiro: Fundação Getúlio Vargas, 1999.

CARNOY, Martin. Escola e trabalho no Estado capitalista. São Paulo: Cortez, 1993.

CARVALHO, José Murilo de. Desenvolvimiento de la ciudadania en Brasil. México: Fondo de Cultura Económica, 1995.

CASTEL, Robert. As metamorfoses da questão social: uma crônica da questão social. Petrópolis: Vozes, 1997. DECLARAÇÃO mundial sobre educação para todos e plano de ação para satisfazer as necessidades básicas de aprendizagem. Nova Iorque: Unicef, 1990.

DINIZ, Eli. Governabilidade, democracia e reforma do Estado: os desafios da construção de uma nova ordem no Brasil dos anos 90. In: .; AZEVEDO, Sérgio de (Orgs.). Reforma do Estado e democracia no Brasil: dilemas e perspectivas. Brasília: Edunb, 1997.

DRAIBE, Sonia M. A política social na América Latina: o que ensinam as experiências recentes de reformas? In: DINIZ, Eli; AZEVEDO, Sérgio de (Orgs.). Reforma do Estado e democracia no Brasil: dilemas e perspectivas. Brasília: Edunb, 1998.

DUARTE, Adriana M. C. Estado, políticas sociais e recomposição de hegemonia: o caso da previdência social. Belo Horizonte: UFMG/FaE, Programa de Pós-Graduação em Educação, Conhecimento e Inclusão, 2002, 276 p. (tese de doutorado).

GIDDENS, Anthony. As consequiências da modernidade. São Paulo: Edunesp, 1991.

HOBSBAWM, Eric John. Era dos extremos: o breve século XX - 1914-1991. 2. ed. São Paulo: Companhia das Letras, 1998.

MILLS, Wright. Educação e classe social. In: PEREIRA, Luiz; FORACCI, Marialice Mencarini. Educação e sociedade: leituras de sociologia da educação. 13. ed. São Paulo: Nacional, 1987. p. 268-286.

OLIVEIRA, Dalila Andrade. Educação e planejamento: a escola como núcleo da gestão. In: Gestão democrática da educação: desafios contemporâneos. 2. ed. Petrópolis: Vozes, 1997. p. 64-104. (Org.). Educação básica: gestão do trabalho e da pobreza. Petrópolis: Vozes, 2000.

POPKEWITZ, Thomas S. Reforma educacional: uma política sociológica. Porto Alegre: Artes Médicas, 1997. SALAMA, Pierre; VALIER, Jacques. Pobrezas e desigualdades no terceiro mundo. São Paulo: Nobel, 1997. 


\title{
Education in the context of present social policies: between focalization and universalization
}

\author{
Abstract
}

This article discusses education as a social policy in the context of the educational reform under way in Brazil since the first half of the 1990s. It starts from the fact that the country has lived an intense process of educational reforms expressed in actions and measures which have altered the configuration of the system as well as the objective of the policies. Based on some theoretical references which are founded on studies and empirical researches, it discusses the processes of the State reform in Latin America countries and thus identifies a clear orientation to focalize the educational policy in Brazil and obeying the same tendency in conducting social policies in general. The study also observes that such orientation is carried out in more complex reforms which involve public administration, adopting models of disregulation and descentralization which allow the focalization of social policies on the poorer populations, to the detriment of universal policies.

Keywords: Educational policies. Social policies. Educational reform. Education. Latin America.

\section{L'éducation dans le contexte des politiques sociales actuelles : entre la focalisation et l'universalisation}

Résumé

Cet article discute l'éducation comme politique sociale dans le contexte de la réforme éducationnelle en cours au Brésil depuis la première moitié des années 1990. Il part de la constatation que le pays a vécu un intense processus de réformes éducationnelles manifestées en actions et mesures qui modifient la configuration du système, bien comme les objectifs des politiques. A partir de quelques références théoriques qui, fondées sur des études et recherches empiriques, discutent les processus de réforme de l'État dans les pays Latino-américains, on identifie une orientation claire de focalisation de la politique éducationnelle au Brésil, qui obéit à la même tendance mise en évidence dans la conduction des politiques sociales en général. L'on observe que cette orientation se réalise au sein de réformes plus complexes qui impliquent l'administration publique. Celle-ci adote des politiques sociales pour les populations pauvres, au détriment de politiques universelles.

Mots clefs : Politique éducationnelle. Politique sociale. Réforme éducationnelle. Éducation. Amérique Latine.

\section{La educación en el contexto de las políticas sociales actuales: entre la focalización y la universalización \\ Resumen}

El presente artículo discute la educación como política social en el contexto de la reforma educacional en Brasil, en curso desde la primera mitad de la década de 1990. Parte de la constatación de que el país vivió un intenso proceso de reformas educacionales, expresado en acciones y medidas que alteraron tanto la configuración del sistema como el objetivo de las politicas. A partir de algunas referencias teóricas que, baseadas en estudios y investigaciones empiricas, discuten los procesos de reforma del estado en los paises de Latinoamérica, identifica una clara orientación de focalización de la politica educacional en Brasil, siguiendo la misma tendencia evidenciada en la conducción de las políticas sociales en general. Observa que tal orientación se realiza en el ámbito de reformas más complejas que involucran la administración pública, adotando modelos de desreglamentación y descentralización que permiten la focalización de las políticas sociales en los más pobres, en detrimento de políticas universales.

Palabras-clave: Politica educacional. Política social. Reforma educacional. Educación. Latinoamérica.

Recebido: 22.02 .2005

Aceito: 10.05 .2005 